\section{Case Reports in Oncology}

\title{
Anterior Mediastinal Leiomyosarcoma: A Case Report and Literature Review
}

\author{
Akira Ishikawa $^{a} \quad K^{2}$ azuya Kuraoka ${ }^{a}$ b Junichi Zaitsu ${ }^{b} \quad$ Akihisa Saito $^{b}$

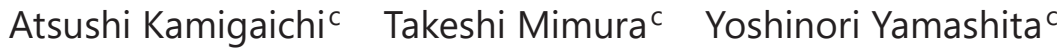 \\ Kiyomi Taniyamad \\ aDepartment of Clinical Laboratory, National Hospital Organization, Kure Medical Center \\ and Chugoku Cancer Center, Kure, Japan; ${ }^{b}$ Department of Diagnostic Pathology, National \\ Hospital Organization, Kure Medical Center and Chugoku Cancer Center, Kure, Japan; \\ 'Department of General Thoracic Surgery, National Hospital Organization, Kure Medical \\ Center and Chugoku Cancer Center, Kure, Japan; ${ }^{d}$ Honorary President, National Hospital \\ Organization, Kure Medical Center and Chugoku Cancer Center, Kure, Japan
}

\author{
Keywords \\ Leiomyosarcoma · Anterior mediastinum · Sarcoma · Histopathology · Immunohistochemical \\ analysis
}

\begin{abstract}
Primary mediastinal sarcomas are extremely rare. Additionally, mediastinal leiomyosarcomas account for approximately $9 \%$ of mediastinal sarcoma cases. Until date, only few cases of anterior mediastinal leiomyosarcomas have been reported. Herein, we report a case of an 85 -year-old female with an anterior mediastinal mass of $15 \mathrm{~mm}$. Histological examination revealed spindle tumor cells showing a fascicular growth pattern. Immunohistochemically, the tumor cells were focal positive for desmin, calponin, and $\alpha$-smooth muscle actin. The pathological diagnosis was leiomyosarcoma. In conclusion, we encountered a case of a very rare leiomyosarcoma that occurred in the anterior mediastinum, and our report may contribute to the understanding of this disease.

(C) 2021 The Author(s).

Published by S. Karger AG, Basel
\end{abstract}

\section{Introduction}

Primary mediastinal sarcomas are extremely rare, with soft tissue sarcomas accounting for less than $1 \%$ of all the tumors [1]. Leiomyosarcomas account for $5-10 \%$ of soft tissue sarcomas [2-4], and mediastinal leiomyosarcomas are found in approximately $9 \%$ of mediastinal sarcomas [5]. Generally, leiomyosarcomas are very aggressive and characterized by 


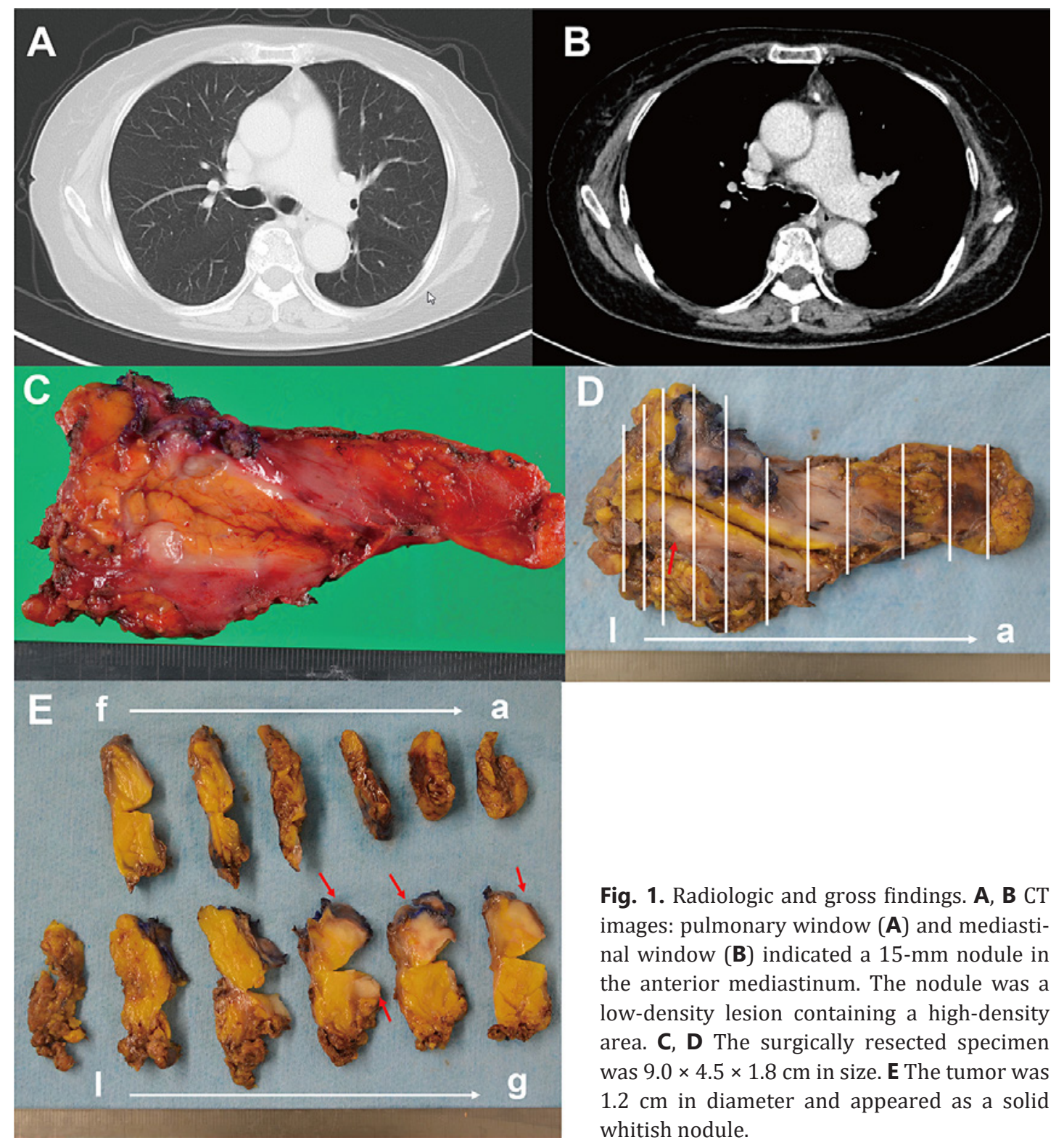

the differentiation of smooth muscle cells. This disease can preferentially occur in the lower extremities, thorax, and head and neck regions [6]. Primary mediastinal sarcomas are mostly derived from mediastinal organs, such as the heart, esophagus, and the blood vessels. Only 7 cases of anterior mediastinal leiomyosarcomas have been reported [7-10]. Here, we report an extremely rare case of anterior mediastinal leiomyosarcoma in an 85-year-old female.

\section{Case Presentation}

An 85-year-old female without known comorbidities presented to our hospital with a mediastinal mass. Five months ago, chest computed tomography scanning had indicated an 8-mm nodule in the anterior mediastinum. Two months prior, the nodule had grown to 15 $\mathrm{mm}$ in size (Fig. 1A-B). Routine laboratory tests were unremarkable. Positron emission 


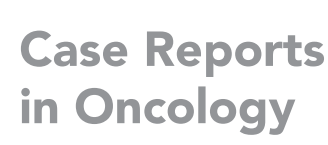

\begin{tabular}{|c|c|}
\hline \multicolumn{2}{|c|}{ 2021;14:101-106 } \\
\hline DOI: $10.1159 / 000509772$ & $\begin{array}{l}\text { (c) } 2021 \text { The Author(s). Published by S. Karger AG, Base } \\
\text { www.karger.com/cro }\end{array}$ \\
\hline
\end{tabular}
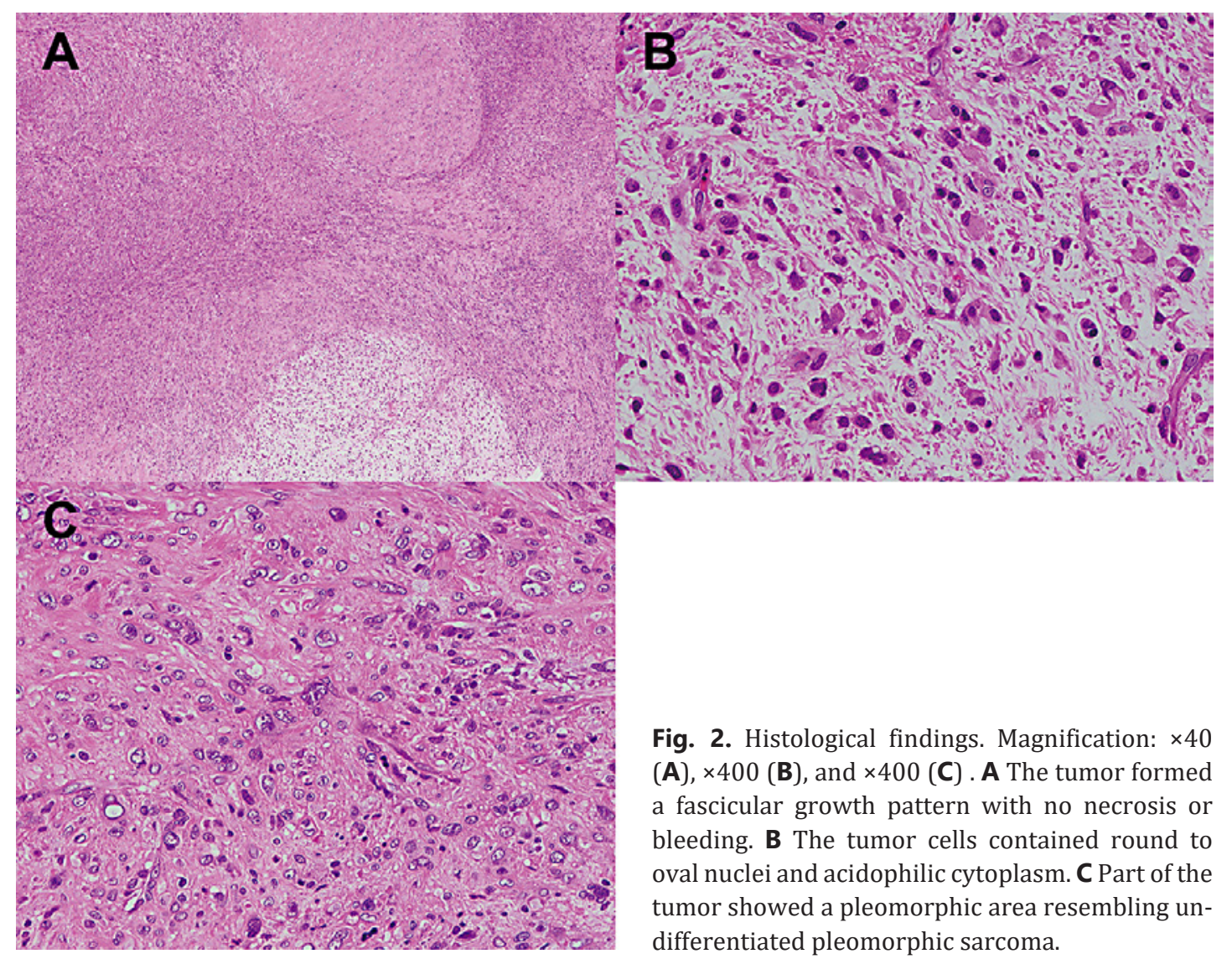

Fig. 2. Histological findings. Magnification: $\times 40$ (A), $\times 400($ B), and $\times 400$ (C). A The tumor formed a fascicular growth pattern with no necrosis or bleeding. B The tumor cells contained round to oval nuclei and acidophilic cytoplasm. C Part of the tumor showed a pleomorphic area resembling undifferentiated pleomorphic sarcoma.

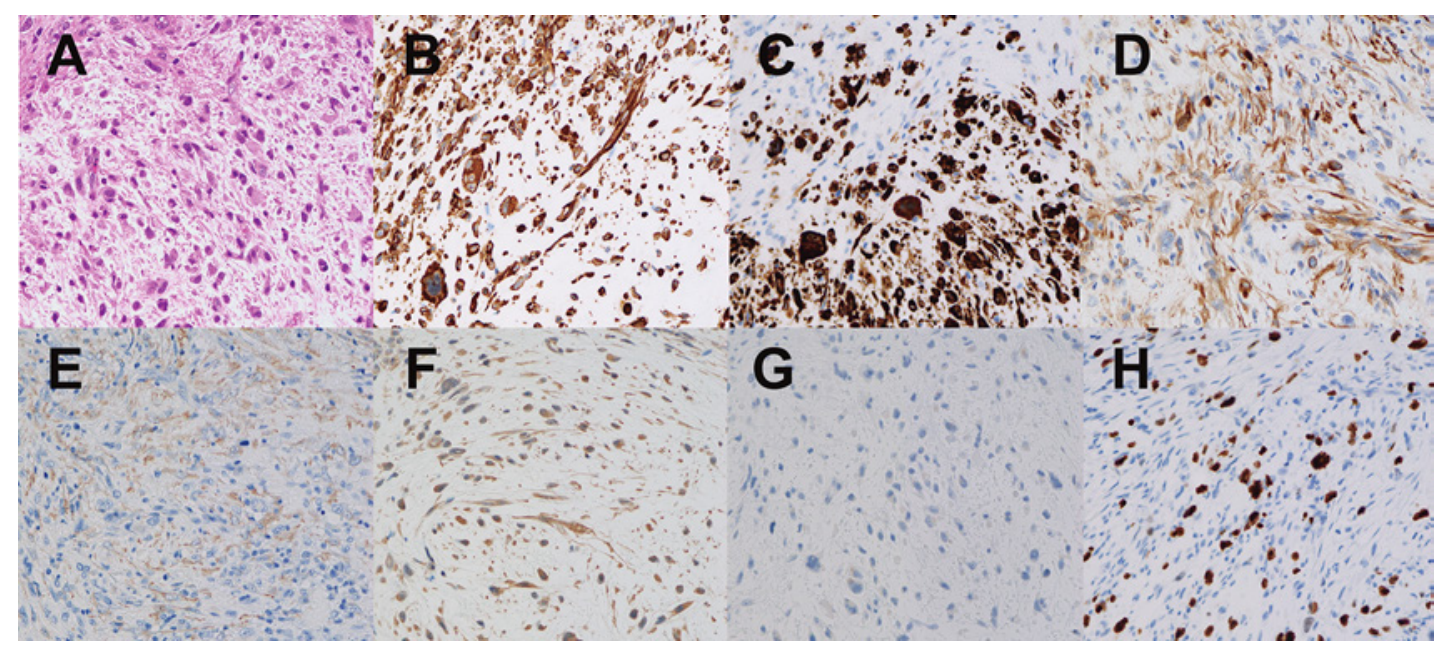

Fig. 3. Immunohistochemistry findings. Magnification: $\times 400$ (A-H). A HE. B Vimentin. C Desmin. D Calponin. E $\alpha$ SMA. F Caldesmon. G CK AE1/AE3. H Ki-67.

tomography-computed tomography scanning revealed slightly strong fluorodeoxyglucose accumulation in the tumor (maximum standardized uptake value 3.41), and no other lesions were detected. Mediastinal tumor resection with the thymus was performed. The surgically resected specimen was $9.0 \times 4.5 \times 1.8 \mathrm{~cm}$ in size (Fig. 1C-D). Gross findings showed that the 
Table 1. Summary of the clinical features of previously reported anterior mediastinal leiomyosarcoma cases and the present case

\begin{tabular}{llllllll}
\hline Case & Age & Sex & Symptoms & Treatment & Follow-up & Size $(\mathrm{cm})$ & Ref \\
\hline 1 & 54 & $\mathrm{~F}$ & None & $\mathrm{Rx}$ & Died at 2 years & $15 \times 10$ & {$[12]$} \\
\hline 2 & 36 & $\mathrm{M}$ & Chest pain & $\mathrm{Rx}$ & Lost to follow-up & $10 \times 10 \times 8$ & {$[14]$} \\
\hline 3 & 26 & $\mathrm{M}$ & Cough, chest pain & $\mathrm{Rx}$ & Details unknown & $16 \times 12 \times 8$ & {$[14]$} \\
\hline 4 & 73 & $\mathrm{M}$ & $\begin{array}{l}\text { Cough, chest pain } \\
\text { Right pleural effusion }\end{array}$ & $\mathrm{Rx}$ & Details unknown & $18 \times 15 \times 12$ & {$[11]$} \\
\hline 5 & 76 & $\mathrm{~F}$ & Decreased breathing & $\mathrm{Rx}$ & Details unknown & $11.4 \times 8.4 \times 13$ & {$[9]$} \\
\hline 6 & 61 & $\mathrm{M}$ & None & $\mathrm{Rx}$ & Lost to follow-up & $5.2 \times 3.3$ & {$[8]$} \\
\hline 7 & 51 & $\mathrm{M}$ & Dyspnea, dysphagia & $\mathrm{Rx}, \mathrm{RT}$ & NED 10 months & $3.5 \times 3$ & {$[11]$} \\
& & & Vena cava syndrome & & & & $1.4 \times 1.3 \times 1.2$ \\
\hline 8 & 85 & F & None & $\mathrm{Rx}$ & Recent case & \\
\hline
\end{tabular}

F, female; M, male; Rx, resected; RT, radiotherapy; NED, no evidence of disease.

tumor was surrounded by mediastinal adipose tissue. The size of the tumor was $1.4 \times 1.3 \times$ $1.2 \mathrm{~cm}$ (Fig. 1E). Histological examinations showed tumor cells with round to oval nuclei and acidophilic cytoplasm forming a fascicular growth pattern (Fig. 2A-B). Part of the pleomorphic area resembled an undifferentiated pleomorphic sarcoma (Fig. 2C). The tumor cells infiltrated the surrounding fatty tissue and pericardium. There was no apparent necrosis or bleeding, and many mitotic figures were observed (11/10 high-power fields). Immunohistochemically, the tumor cells were positive for vimentin, focal positive for desmin, calponin, and $\alpha$-smooth muscle actin, and negative for CDK4, CD34, MDM2, Caldesmon, myogenin, and AE1/AE3. The Ki-67 positivity rate was approximately 40\% (Fig. 3A-H). The pathological diagnosis was leiomyosarcoma (Federation Nationale des Centres de Lutte le Cancer Grade 2, pT1b (soft tissue sarcoma, TNM/UICC scoring)). After resection, the patient was followed up and showed no recurrence or metastasis.

\section{Discussion}

Mediastinal leiomyosarcoma is a very rare tumor with less than 50 cases reported as case reports and a few small case series [7-13]. This tumor occurs typically in the posterior mediastinum [9]. Cases in the anterior mediastinum are extremely rare [7-10, 12]. The clinicopathological features of the 7 previously reported cases are summarized in Table 1 . The tumor size can reach $18 \mathrm{~cm}$. Most mediastinal leiomyosarcomas show no specific symptoms but are caused by superior vena cava syndrome in some cases $[10,14]$. In our case, the patient showed no symptoms, possibly because of the small size of the tumor.

Leiomyosarcomas are divided into several site-related subgroups based on their clinical and biological differences. The subgroup classification includes the retroperitoneum and abdominal cavity subgroup, somatic soft tissue subgroup, and vascular origin subgroup. Most cases fall into the retroperitoneum and abdominal cavity subgroup and show aggressive outcomes. The somatic soft tissue subgroup is associated with better prognosis, whereas cases in the vascular origin subgroup are rare. In some cases, mediastinal leiomyosarcomas 
were reported to originate from major vessels rather than from mediastinal soft tissue [14]. Other possible origins include cystic lesions such as a bronchogenic cyst [13]. In our case, the leiomyosarcoma was classified into the somatic soft tissue subgroup because it occurred in the anterior mediastinum and was not adjacent to the pulmonary artery or vena cava.

Leiomyosarcoma must be distinguished from other spindle cell sarcomas, particularly synovial sarcoma and malignant peripheral nerve sheath tumors [15]. Although well-differentiated leiomyosarcomas are likely to show staining of both smooth muscle actin and desmin, less differentiated cases may show diminished staining or loss of smooth muscle markers. In this case, according to hematoxylin and eosin staining, the tumor showed a poorly differentiated sarcoma, such as liposarcoma or undifferentiated pleomorphic sarcoma. Based on the immunohistochemical analysis results, the patient was diagnosed with leiomyosarcoma.

We observed a very rare leiomyosarcoma occurring in the anterior mediastinum. As the number of such cases is small, reporting of more cases will enable investigation of the biological dynamics of this disease or lead to improvements in the prognosis of patients.

\section{Acknowledgements}

The authors would like to thank the patient for allowing us to report her clinical information and data. We gratefully acknowledge the technical assistance of the following clinical technologists: Yasumura N., Kan A., Fujisawa H., Iwahiro K., and Kimura F.

\section{Statement of Ethics}

The case was approved by Kure Medical Center and Chugoku Cancer Center. Written informed consent was given by the patient to publish his case information and details.

\section{Conflict of Interest Statement}

The authors declare that there is no conflict of interest.

\section{Funding Sources}

The authors received no financial support for the research, authorship, or publication of this article.

\section{Author Contributions}

A.I. made substantial contribution to the concept and design of the study, and to data acquisition and interpretation. K.T., J.Z., A.S., A.K., T.M., and Y.Y. were involved in drafting the manuscript and critical revision for intellectual content. K.K. approved the final version of the manuscript submitted for publication. All authors read and approved the final manuscript. 


\section{References}

1 Siegel RL, Miller KD, Jemal A. Cancer statistics, 2019. CA A Cancer J Clin. 2019;69(1):7-34.

2 Gustafson P, Willén H, Baldetorp B, Fernö M, Akerman M, Rydholm A. Soft tissue leiomyosarcoma. A population-based epidemiologic and prognostic study of 48 patients, including cellular DNA content. Cancer. 1992 Jul;70(1):114-9.

3 Wile AG, Evans HL, Romsdahl MM. Leiomyosarcoma of soft tissue: a clinicopathologic study. Cancer. 1981 Aug; 48(4):1022-32.

4 Farshid G, Pradhan M, Goldblum J, Weiss SW. Leiomyosarcoma of somatic soft tissues: a tumor of vascular origin with multivariate analysis of outcome in 42 cases. Am J Surg Pathol. 2002 Jan;26(1):14-24.

5 Burt M, Ihde JK, Hajdu SI, Smith JW, Bains MS, Downey R, et al. Primary sarcomas of the mediastinum: Results of therapy. J Thorac Cardiovasc Surg. 1998;115(3):671-80.

6 Clark MA, Fisher C, Judson I, Thomas JM. Soft-tissue sarcomas in adults. N Engl J Med. 2005 Aug;353(7):70111.

7 Xue X, Liang W, Zhang W. Anterior mediastinal leiomyosarcoma mimicking thymoma: A case report. Med (United States). 2018 Jun;97(25):15-7.

8 Liao CY, Chien ST, Huan SF. Primary leiomyosarcoma of the anterior mediastinum. Qjm. 2015 May; 108(5): 429-30.

9 Hirano H, Kizaki T, Sashikata T, Maeda T, Yoshii Y. Leiomyosarcoma arising from soft tissue tumor of the mediastinum. Med Electron Microsc. 2003;36(1):52-8.

10 Labarca E, Zapico A, Ríos B, Martinez F, Santamarina M, Ríos B, et al. Superior vena cava syndrome due to a leiomyosarcoma of the anterior mediastinum: A case report and literature overview. Int J Surg Case Rep. 2014; 5(12):984-7.

11 Iwata T, Miura T, Inoue K, Hanada S, Inoue H, Miyamoto Y. Primary leiomyosarcoma of the anterior mediastinum encasing the aortic arch, left common carotid and left subclavian arteries. Ann Thorac Cardiovasc Surg. 2012;18(2):140-3.

12 Moran CA, Suster S, Perino G, Kaneko M, Koss MN. Malignant smooth muscle tumors presenting as mediastinal soft tissue masses. A clinicopathologic study of 10 cases. Cancer. 1994;74(8):2251-60.

13 Kimura K, Ogawa H, Jimbo N, Hokka D, Tanaka Y, Maniwa Y. A case of leiomyosarcoma originating from a bronchogenic cyst: A case report. Mol Clin Oncol. 2020 Mar;12(3):244-6.

14 Sunderrajan EV, Luger AM, Rosenholtz MJ, Maltby JD. Leiomyosarcoma in the mediastinum presenting as superior vena cava syndrome. Cancer. 1984 Jun;53(11):2553-6.

15 den Bakker MA, Marx A, Mukai K, Ströbel P. Mesenchymal tumours of the mediastinum--part II. Virchows Arch. 2015;467(5):501-17. 